\title{
Variation and genetic studies on selected sweet corn inbred lines
}

\begin{abstract}
Nine advanced tropical sweet corn (Zea mays L.saccharata) inbred lines were evaluated to determine their performance, to estimate broad-sense heritability of the traits measured and to determine phenotypic correlations among the traits. The inbred lines showed a wide range of performance for husked fresh ear yield and its components. Based on performance and earliness, inbred lines Bakti-1-S7, TSS Melaka-S5, Thailand-S6, MM x Indonesia-S4 and Manis Madu-S7 were found to be superior and could be short-listed for further testing for general and specific combining ability analysis towards development of hybrid varieties. Broad-sense heritability (h2B) estimates obtained from the variance components method were found to be high for number of days to silking (80.5\%), plant height (79.9\%), number of days to tasseling (66.9\%) and ear height (63.7\%), moderate for husked ear yield $(56.7 \%)$, total soluble solid concentration $(54.2 \%)$, number of kernel rows per ear $(53.9 \%)$, ear diameter $(46.7 \%)$, dehusked ear yield (43.1\%), number of kernels per row $(42.6 \%)$ and number of ear per hectare $(34.5 \%)$, while lowest estimates for dehusked ear length (12.9\%) and husked ear length $(0.3 \%)$. Traits found to be highly correlated with husked ear yield were dehusked ear yield (0.97), number of kernel rows per ear (0.71), plant height (0.69), husked ear length (0.67), ear height (0.66), dehusked ear length (0.63), ear diameter $(0.55)$, number of kernels per row (0.50) and number of ears per hectare (0.49). For selection purposes, it is therefore suggested that emphasis should be given on traits like number of kernel rows per ear, plant and ear height and ear length for yield improvement among the inbred lines.
\end{abstract}

Keyword: Zea mays L. saccharata; Inbred line; Heritability; Correlation 